\title{
IMPORTANT AND PERFORMANCE ANALYSIS TINGKAT KEPUASAN MAHASISWA PROGRAM D-3 EKONOMI TERHADAP KINERJA PROGRAM D-3 EKONOMI
}

\author{
Oleh: \\ Khusniyah Purwani
}

ABSTRACT

The research on students satisfaction towards performance of Program Diploma III Ekonomi UII uses four variables, namely curriculum, lectures, facilities, and service. The research respondent were students of Program Diploma III Ekonomi covering those of management, accounting, and banking finance. Importance and Performance Analysis (IPA) methode used to analysis research data.

The reason behind the research was Program Diploma III Ekonomi's desire and hope to assess and evaluate the performance of the program so far. It was hoped that the research findings can be used as a reference to improve the situation in the future. On the other hand, the program have commited to place consumer's satisfaction orientations as the main goal of the program as education institution.

The research finding shows that as many as $31 \%$ or 13 attributes whe main priorities to get attention and improvement. These attributes consisted of computer lab facilities, lecture room facilities, lab assistants, hot spot area, punctuality of the lectures service of Program D-3 Management, facilities of subject supporting lab. (Bank Lab, Management Lab, and Accounting Lab.), service of academy administration staff, the arrangement of computer lab, service of finance administration staff, lectures ending lectures within tolerance threshold (reducing or prolonging hours too much), availability of practicum modules, and application of subjects through practicum.

Key Word: Satisfaction, Important and Performance Analysis. 
Yogyakarta sebagai kota pendidikan telah terkenal di Indonesia. Predikat sebagai kota pendidikan membawa konsekuensi bahwa semua lembaga penyelenggara pendidikan yang berada di Yogyakarta akan menjadi barometer penyelenggara pendidikan di kota-kota lain selain Yogyakarta. Pendidikan tidak hanya memperhatikan penyaringan input yang berkualitas, proses pembelajaran yang efektif dan tepat, namun juga mempunyai target bahwa lulusan yang dihasilkan akan sesuai dengan kebutuhan pengguna lulusan di pasar tenaga kerja. Sebagai șebuah organisasi penyelenggara pendidikan, perguruan tinggi tetap dituntut untuk berorientasi kepada kepuasan konsumen (customer satisfaction) yakni berorientasi kepada kepuasan mahasiswa.

Mahasiswa sebagai input pendidikan, atau material yang diproses dan sekaligus menjadi output proses pendidikan akan merasakan proses pembelajaran dan pelayanan pendidikan dengan seluruh interaksinya di dalam sebuah organisasi/ perusahaan. Pengalaman (experience) mahasiswa selama mengikuti proses pendidikan yang diberikan oleh penyelenggaran pendidikan akan membentuk menjadi prior experience dalam mengkonsumsi produk. Prior experience ini akan muncul/ teringat kembali ketika seorang konsumen (mahasiswa) merasakan adanya kebutuhan akan jasa pendidikan. Pelayanan pendidikan yang didesain penyelenggara pendidikan akan menjadi perhatian konsumen (mahasiswa/ masyarakat). Mengaca dari kenyataan ini maka institusi penyelenggara pendidikan perlu mengevaluasi kembali strategi kualitas yang dikemasnya dalam penyampaian kurikulum (produk), dosen (personel), fasilitas sarana prasarana dan pelayanan civitas akademikanya (service). Dalam kondisi persaingan yang ketat ini, hal utama yang harus diprioritaskan oleh sebuah perguruan tinggi adalah kepuasan mahasiswa agar tetap dapat bertahan (survive), bersaing, menguasai ilmu pengetahuan dan teknologi pendidikan. Pemberian fasilitas sarana prasarana yang belum memadai, serta pelayanan yang diberikan oleh seluruh personel yang ada di dalam institusi penyelenggara pendidikan (pengelola, dosen dan karyawan) yang belum optimal akan mempunyai pengaruh yang besar dalam proses belajar mengajar dan pencapaian target lulusan.

Terkait dengan kondisi dan tuntutan kepuasan konsumen (mahasiswa) ini, maka peneliti telah meneliti sejauh mana tingkat kepuasan mahasiswa Program Diploma-3 Ekonomi Ull ini menilai kinerja Program Diploma-3 Ekonomi UII. Hasil penelitian akan memberikan gambaran evaluasi strategi pemasaran yang telah dilakukan selama ini dan merupakan sumbang saran kepada pengelola Program Diploma-3 dalam mengemas strategi pemasaran pendidikan berikutnya. 


\section{| \\ B. RUMUSAN MASALAH \\ Berdasarkan uraian di atas, maka penulis merumuskan masalah yang menjadi pokok dalam penelitian, adalah : \\ 2.1. Sejauh mana tingkat kepuasan mahasiswa Program D-3 Ekonomi UII terhadap kinerja Program D-3 Ekonomi Ull berdasarkan kenyataan jasa yang diterima oleh mahasiswa (kinerja) dan jasa yang diharapkan oleh mahasiswa (kepentingan/harapan)}

2.2. Variabel apakah yang menjadi prioritas utama yang perlu dilakukan peningkatan secara terus menerus (Continual Improvement) oleh Program D-3 Ekonomi UII.

\section{C.1. Pengertian Kepuasan, Kualitas Jasa}

Kepuasan adalah tingkat perasaan seseorang setelah membandingkan kinerja/ hasil yang dirasakan dengan harapannya (Oliver, 1997). Tingkat kepuasan merupakan fungsi dari perbedaan antara kinerja yang dirasakan dengan harapan. Pelanggan akan kecewa, bila kinerja tidak sesuai harapan, pelanggan akan puas apabila kinerja yang diterima sesuai dengan harapan dan pelanggan akan sangat puas apabila kinerja yang diterima melebihi apa yang diharapkan. Pelanggan yang puas bahkan sangat puas akan memberikan sumbangan yang besar dalam membentuk loyalitas pada diri konsumen.

Persepsi konsumen mengenai kualitas jasa (service quality) adalah hasil perbandingan antara persepsi konsumen mengenai service yang seharusnya diterima oleh konsumen dengan kinerja riil yang ditawarkah oleh penyedia jasa (Parasuraman et.al.,(1988). Lima dimensi service experience yang diperkenalkan oleh Parasuraman yang dikenal dengan model service quality (SERVQUAL) terdiri dari reliability, responsiveness, empathy, assurance, and tangibility. Service quality juga didefinisikan sebagai hasil perbandingan antara jasa yang diterima dengan jasa yang diharapkan (Grönroos, 1984).

Kepuasan pelanggan dan kualitas jasa'telah diakui sebagai dua faktor yang berperanan dalam membentuk loyalitas konsumen (Anderson and Mittal (2000) dalam Caceres, R.C. dan Nicholas G.P.(2007). Sementara itu kualitas menjadi faktor pokok di dalam customer satisfaction (Sullivan, (1993), dalam Caceres, R.C. dan Nicholas G.P.,(2007). Oleh karenanya setiap perusahaan yang ingin tetap eksis harus memberikan perhatian yang lebih guna perbaikan terus menerus dalam pemberian jasa. Loyalitas konsumen (loyality) dipengaruhi oleh kualitas jasa (service quality) yang terdiri dari technical quality dan functional quality, sedangkan kualitas hubungan jasa (relationship quality) terdiri dari trust dan commitment (Caceres, R.C. dan Nicholas G.P. 2007). Pola hubungan itu tersaji dalam Gambar 1. Customer loyality. 
Loyalitas konsumen merupakan faktor kunci kesuksesan suatu bisnis. Perusahaan-perusahaan harus mencari tahu bagaimana caranya meningkatkan dan mempertahankan loyalitas konsumennya demi keberlanjutan perusahaan dalam jangka panjang. Dalam persaingan dewasa ini kesuksesan perusahaan dapat diraih dengan strategi penyampaian jasa (service) yang berkualitas. Hal ini akan diperkuat dengan adanya relationship quality yang baik atau kualitas hubungan di dalam proses penyampaian jasa kepada konsumen.

\section{Gambar 1.}

\section{Customer Loyality}

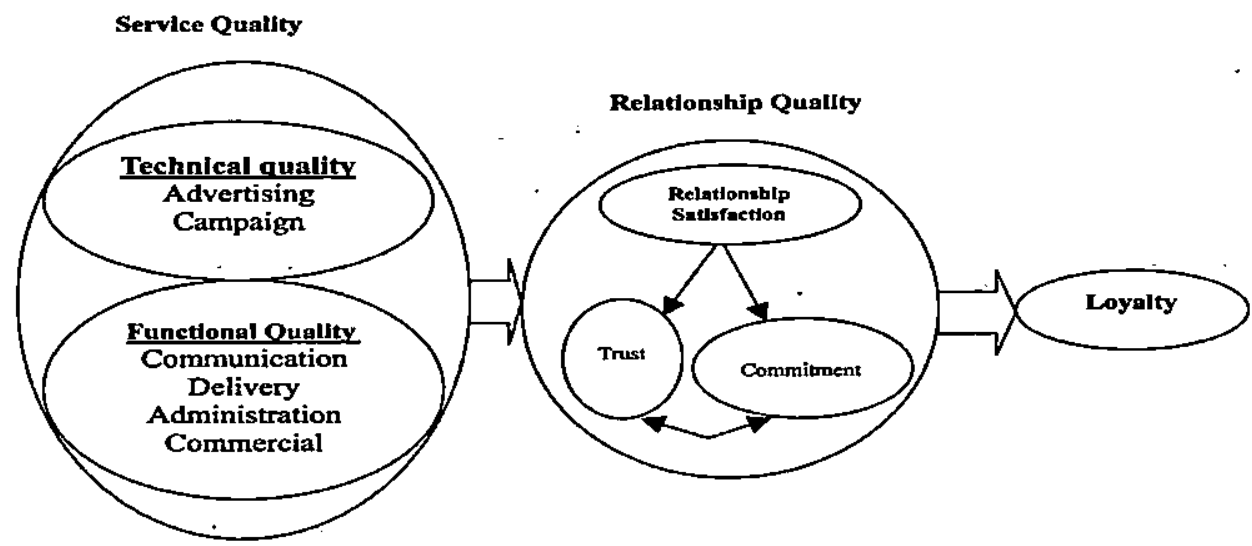

Sumber: Caceres, R.C. and Nicholas G.P, 2007

Service quality dan customer satisfaction dapat dicapai dengan mengelola kinerja atribut-atribut jasa/ pelayanan (service attributes). Namun demikian tidak semua atribut jasa/ pelayanan mempunyai pengaruh yang sama dalam memenuhi kebutuhan kepuasan konsumen. Hal ini menjadi pertimbangan utama perusahaan dalam mengelola kinerja agar dapat berdampak pada kepuasan konsumen. Artinya perusahaan haruslah mengevaluasi tingkat kepentingan atribut jasa/ pelayanan bagi konsumen dan mengevaluasi kinerja dari masing masing atribut jasa untuk merencanakan perbaikan kualitas.

\section{C.2. Relationship Satisfaction}

Relationship satisfaction didefinisikan sebagai sebuah pernyataan yang berpengaruh positif dari pernilaian terhadap seluruh aspek yang dimiliki perusahaan hubungannya dengan perusahaan lain. Kesuksesan relationship bisnis diperkuat oleh kepuasan klien dan diperkuat pula dengan kinerja perusahaan. Crosby dan Stevens (1987), mengidentifikasi ada tiga tingkatan dari relationship satisfaction, yakni: 
Khusniyah Purwani: Important and Performance Analysis...

1. Interactions with personnel.

2. Core senvice.

3. The organization.

Hal yang sama yang dilakukan dalam sebuah perguruan tinggi, perbaikan kualitas jasa/ pelayanan dapat direncanakan terstruktur dari seluruh komponen yang terlibat di dalam perguruan tinggi. Atribut-atribut yang terlibat dalam penyediaan penyampaian jasa/ pelayanan kepada konsumen (mahasiswa) dibagi kedalam tiga kategori, yakni :

1. Interaksi dengan personnel, meliputi interaksi dengan mahasiswa, dosen dan karyawan Program Diploma-3 Ekonomi UII

2. Core service, yang diwujudkan dalam desain kurikulum program studi, jasa/ pelayanan sarana prasarana dan fasilitas yang disediakan program, dan

3. The organization, yang dimaksud adalah organisasi Program Diploma-3 Ekonomi UII sebagai sebuah organisasi perusahaan penyelenggaran pendidikan.

Untuk mendapatkan loyalitas mahasiswa, melalui tercapainya kepuasan konsumen (mahasiswa) demi keberlanjutan organisasi Program Diploma-3 Ekonomi UlI maka kepuasan mahasiswa menjadi target utama dalam kegiatan pemasaran dan penyampaian jasa/ pelayanan pendidikan. Jika seorang mahasiswa merasa puas atas pelayanan yang telah diberikan, diharapkan akan tercapai loyalitas mahasiswa terhadap Program Diplorna-3 Ekonomi UII. Lebih lanjut diharapkan bahwa pada umumnya mahasiswa yang loyal akan menginformasikan perasaan puas yang dirasakannya kepada teman atau orang lain. Mahasiswa yang loyal tidak akan berpindah atau kecil kemungkinan akan melakukan pencarian lagi (variety seeking) ke perguruan tinggi lain. Oleh karena itu Program perlu menilai dan mengevaluasi kinerja yang selama ini telah dijalankan. Hasil evaluasi dapat digunakan sebagai dasar pertimbangan perencanaan penyampaian jasa/ pelayanan kepada mahasiswa pada periode yang akan datang.

\section{C.3. Metode Analisis Data}

Metode analisis data yang digunakan dalam penelitian kepuasan pelanggan ini adalah Importance Performance Analysis (IPA) yang pada awalnya dikenalkan oleh Martilla and James (1977). Lebih dikenal dengan analisis tingkat kepentingan dan kinerja kepuasan konsumen. Analisis ini melihat sebuah perusahaan dalam mencermati atribut-atribut produk atau jasa yang harus ditingkatkan agar perusahaan mampu bersaing di pasar. Data yang diolah berasal dari survei kepuasan konsumen yang untuk selanjutnya dibangunlah sebuah matrik, di mana sumbu $Y$ menunjukkan importance dan sumbu $\mathrm{X}$ menunjukkan performance atau kinerja perusahaan (Gamlıar 2. IPA). 
Gambar 2.

Importance Peformance Analysis

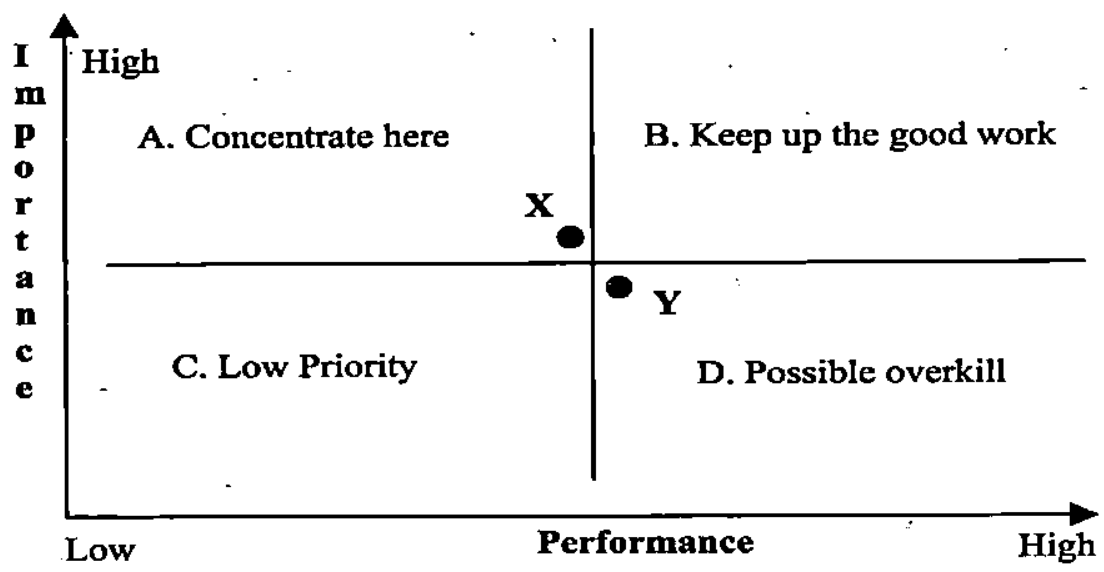

Source: Martilla and James (1977)

Matrix IPA dibagi menjadi empat kuadran, sebagai berikut:.

(1) A. High importance-low performance

(2) B. High importance-high performance

(3) C. Low importance-low performance

(4) D. Low importance-high performance

Quadrant A (concentrate here) memiliki high importance tetapi low performance, kuadran ini menunjukkan bahwa harus segera mendapatkan perhatian, di sinilah letak kelemahan perusahaan yang utama (major weakness).

Quadrant B (keep up the good work) adalah high importance dan high performance, menunjukkan keunggulan kompetitif yang dimiliki perusahaan, harus dipertahankan (major strength).

Quadrant C (low priority) terdiri dari atribut-atribut dengan tingkat low importance dan low performance, kuadran ini tidak membutuhkan usaha tambahan terhadapnya (minor weakness).

Quadrant D (possible overkill) lebih difokuskan pada atribut-atribut dengan high performance tetapi rendah tingkat kepentingannya/ low importance. Dalam kuadran ini perusahaan membuang buang sumber daya yang dapat lebih bermanfaat apabila digunakan di tempat lain (minor strength) (Gambar 3. Empat Kuadran IPA). 
Khusniyah Purwani: Important and Performance Analysis...

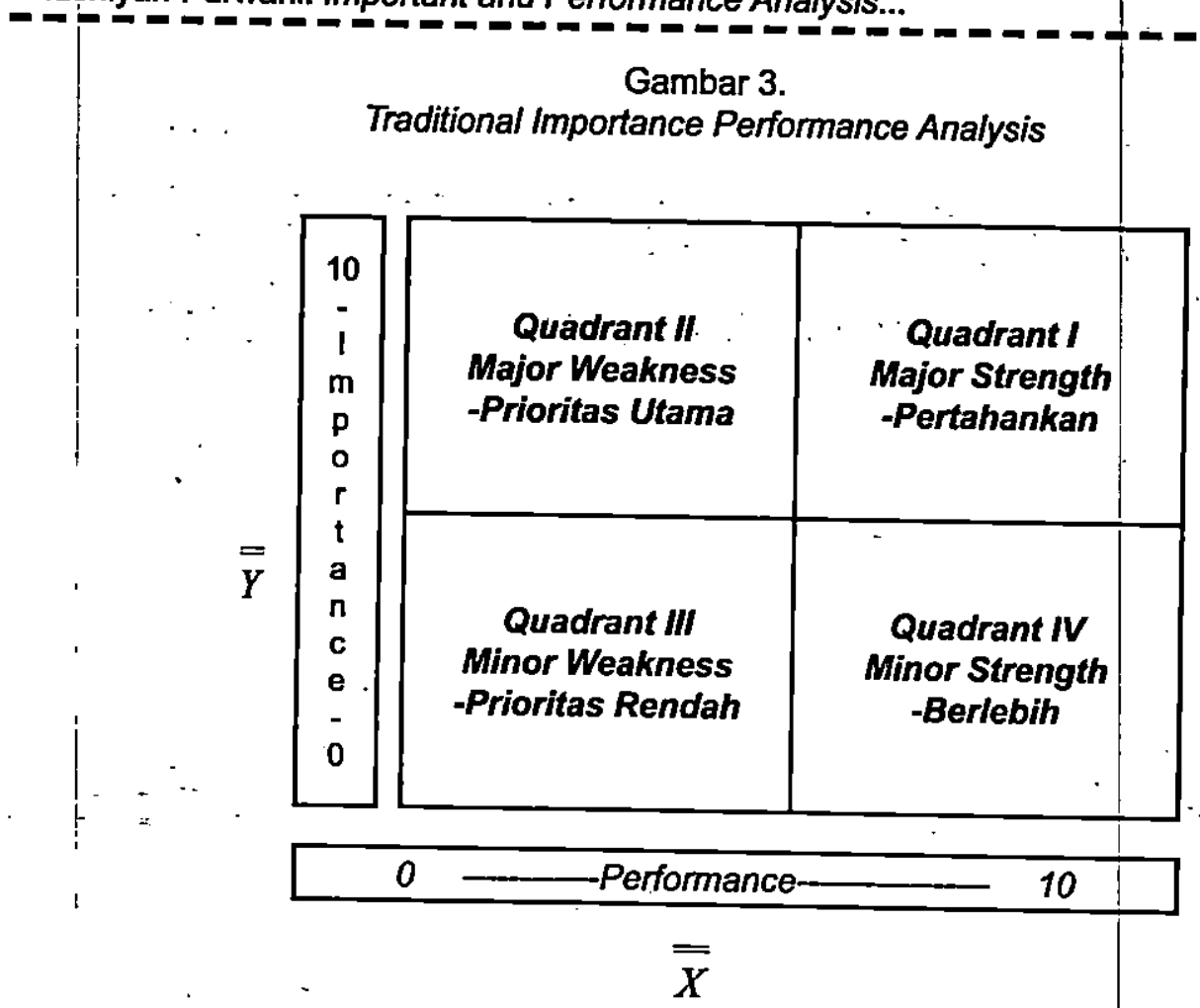

Sumber : Tontini, G dan Silveira, A.(2007).

Jasa akan menjadi sesuatu yang bermanfaat apabila didasarkan pada kepentingan pelanggan dan kinerjanya bagi perusahaan. Artinya perusahaan seharusnya mencurahkan perhatiannya pada hal-hal yang memang dianggap penting oleh para pelanggan/ mahasiswa. Dalam hal ini, digunakan skala Likert 5 tingkat yang terdiri dari: Sangat penting, Penting, Netral, Kurang penting dan Tidak penting. Ke-lima penilaian terhadap tingkat kepentingan (importance) dan kenyataan/ kinerja (performance) tersebut diberi bobot sebagai berikut :

a. Jawaban Sangat Setuju diberi bobot 5, berarti mahasiswa sangat puas

b. Jawaban Setuju diberi bobot 4 , berarti mahasiswa puas

c. Jawaban Netral diberi bobot 3 , berarti mahasiswa netral

d. Jawaban Kurang Setuju diberi bobot 2, berarti mahasiswa kurang puas

e. Jawaban Tidak Setuju diberi bobot 1 , berarti mahasiswe. tidak puas 
Berdasarkan hasil penilaian tingkat kepentingan dan hasil penilaian kinerja maka akan dihasilkan suatu perhitungan mengenai tingkat kesesuaian antara tingkat kepentingan (importance) dan tingkat pelaksanaan (performance) Program Diploma III Ekonomi UII. Tingkat kesesuaian adalah hasil perbandingan skor kinerja pelaksanaan dengan skor kepentingan. Tingkat kesesuaian inilah yang akan menentukan urutan prioritas peningkatan faktor-faktor yang mempengaruhi kepuasan mahasiswa. Dalam hal ini terdapat 2 buah variabel yang diwakilkan oleh huruf $X$ dan $Y$, dimana: $X$ merupakan tingkat kinerja Program Diploma yang dapat memberikan kepuasan kepada mahasiswa, sedangkan $Y$ merupakan tingkat kepentingan atau harapan mahasiswa. Adapun rumus yang dipergunakan dalam pengukuran Tingkat Kesesuaian Responden (TKR) adalah

$$
T K R=\left(\frac{\sum_{i=1}^{n} X_{i}}{\sum_{i=1} Y_{i}}\right) \cdot 100 \%
$$

Dimana, TKR adalah Tingkat Kesesuaian Responden $(i=1,2, \ldots \ldots \ldots \ldots \ldots . . . n)$. $X i$ adalah Skor penilaian kinerja Progam Diploma, dan $Y i$ adalah Skor penilaian kepentingan mahasiswa.

Sumbu mendatar $(X)$ akan diisi oleh skor tingkat pelaksanaan, sedangkan Sumbu tegak $(Y)$ akan diisi oleh skor tingkat yang mempengaruhi kepuasan mahasiswa dengan

$$
\bar{X}=\frac{\sum_{i=1}^{n} X_{i}}{n} \quad \text { dan } \bar{Y}=\frac{\sum_{i=1}^{n} Y_{i}}{n} .
$$

Dimana $\bar{X}$ adalah Skor rata-rata tingkat kepuasan, dan $\bar{Y}$ adalah Skor rata-rata tingkat kepentingan dan $\mathrm{n}$ adalah Jumlah sampel.

Diagram kartesius merupakan suatu bangun yang dibagi atas empat bagian yang dibatasi oleh dua buah garis yang berpotongan tegak lurus pada titik-titik $(\overline{\overline{X, Y}})$, dimana $\overline{\bar{X}}$ merupakan rata-rata dari rata-rata skor tingkat kepuasan mahasiswa seluruh faktor atau atribut dan' $Y$ 'merupakan rata-rata skör tingkat kepentingan seluruh faktor yang mempengaruhi kepuasan mahasiswa. 


\section{D.1. Data Penelitian}

Data penelitian ini diperoleh dengan menyebarkan kuesioner kepada mahasiswa Program Diploma III Ekonomi UII sebagai responden, di ketiga program studi. Teknik non probability sampling digunakan dalam untuk memenuhi jumlah.sampél yang diperlukan pada ketiga program studi. Kuesioner yang disebar sebanyak 250 kuesioner, untuk prodi akuntansi disebarkan kuesioner sebanyak 115, prodi manajemen sebanyak 80 kuesioner dan prodi keuangan perbankan disebarkan 55 kuesioner. Dari jumlah kuesioner yang disebarkan tersebut, prodi akuntansi kembali 75 kuesioner dengan rincian 72 kuesioner layak untuk diolah, sementara 3 kuesioner gugur. Dari prodi manajemen sebanyak 80 kuesioner, temyata 36 kuesioner kembali, 32 kuesioner layak untuk diolah, sementara itu 4 kuesioner gugur. Untứk program studi keuangan perbankan disebar sebanyak 55 kuesioner, 44 kulesioner kembali, terdiri dari 40 kuesioner layak untuk diolah, sementara 4 kuesioner tidak layak untuk diolah. Dengan demikian jumlah kuesioner yang layak untuk diolah ada sebanyak 144 kuesioner (Tabel 1. Penyebaran Kuesioner).

Tabel 1.

Penyebaran Kuesioner

\begin{tabular}{|c|c|c|c|c|c|c|c|}
\hline \multirow{2}{*}{ Program Studi } & \multirow{2}{*}{ Sebar } & \multicolumn{6}{|c|}{ Kuesioner } \\
\hline & & $\%$ kembali & Kembali & $\%$ layak & Layak & gugur & Gugur \\
\hline Akunțansi & 115 & $65 \%$ & 75 & $96 \%$ & 72 & $4 \%$ & 3 \\
\hline Manajemen & 80 & $45 \%$ & 36 & $89 \%$ & 32 & $13 \%$ & 4 \\
\hline Keu. Perbankan & 55 & $8 \%$ & 44 & $91 \%$ & 40 & $10 \%$ & 4 \\
\hline ' & 250 & & 155 & . & 144 & $8 \%$ & 11 \\
\hline
\end{tabular}

Sumber: data primer peneliti

Kuesioner yang disebarkan adalah kuesioner yang bersifat tertutup. Dengan demikian untuk setiap pertanyaan disediakan jawaban alternatif yang paling tepat sesuai dengan pendapat responden.

\section{D.2. Pengujian Kualitas Data}

Kesahihan (validitas) dan keandalan (reliabilitas) penelitian ini ditentukan melalui uji validitas dan reliabilitas terhadap instrumen penelitiannya. Uji ini dipakai untuk mengetahui seberapa valid dan reliable setiap itt !m pertanyaan di dalam kuesioner dan tes skala. Jumlah item pertanyaan dalam kuesioner berjumlah 45 item pertanyaan. Rincian item pertanyaan padal masing masing variabel adalah variabel kurikulum dengan 16 item pertanyaan, variabel dosen terdiri dari 13 item pertanyaan, variabel fasilitas terdiri dari 9 item dan variabel pelayanan dengan 7 item pertanyaan. 


\section{D.2.1. Uji Validitas}

Kesahihan digunakan untuk mengukur apa yang seharusnya diukur. Uji kesahihan (validitas) penelitian ini menggunakan matriks Correlation Coefficient of Product Moment Pearson dengan alat bantu perhitungan program SPSS for Windows release 13.0. Uji Pearson digunakan untuk mengkorelasikan skor per item dengan skor totalnya. Dari hasil pengujian korelasi Product Moment Pearson diperoleh hasil sbb:

Tabel 2.

Hasil Uji Kesahihan

\begin{tabular}{|c|c|c|c|c|c|c|c|}
\hline Butir & $\begin{array}{l}\text { Korelasi } \\
\text { Pearson }\end{array}$ & Sig. & Ket. & Butir & $\begin{array}{l}\text { Korelasí } \\
\text { Pearson }\end{array}$ & Sig. & Ket. \\
\hline K1(Kurikulum) & 0,501 & 0,01 & Valid & F1(Fasilitas) & 0,664 & 0,01 & Valid \\
\hline $\mathrm{K} 2$ & 0,549 & 0,01 & Valid & F2 & 0,721 & 0,01 & Valid \\
\hline $\mathrm{K} 5$ & 0,599 & 0,01 & Valid & F3 & 0,678 & 0,01 & Valid \\
\hline K6 & 0,674 . & 0,01 & Valid & $\mathrm{F} 4$ & 0,617 & 0,01 & Valid \\
\hline $\mathrm{K} 7$ & 0,628 & 0,01 & Valid & F5 & 0,523 & 0,01 & Valid \\
\hline $\mathrm{K} 8$ & 0,673 & 0,01 & Valid & F6 & 0,749 & $\overline{0,01}$ & Valid \\
\hline $\mathrm{K} 9$ & 0,548 & 0,01 & Valid & $\mathrm{F7}$ & 0,688 & 0,01 & Valid \\
\hline $\mathrm{K} 10$ & 0,491 & 0,01 & Valid & F8 & 0,601 & 0,01 & Valid \\
\hline K11 & 0,474 & 0,01 & Valid & F9 & 0,498 & 0,01 & Valid \\
\hline $\mathrm{K} 12$ & 0,604 & 0,01 & Valid & P1(Pelayanan) & 0,725 & 0,01 & Valid \\
\hline K13 & 0,532 & 0,01 & Valid & $\mathrm{P} 2$ & 0,775 & 0,01 & Valid \\
\hline K14 & 0,559 & 0,01 & Valid & P3 & 0,815 & 0,01 & Valid \\
\hline K15 & 0,630 & 0,01 & Valid & P4 & 0,758 & 0,01 & Valid \\
\hline K16 & 0,649 & 0,01 & Valid & P5 & 0,713 & 0,01 & Valid \\
\hline D1(Dosen) & 0,585 & $0 ; 01$ & Valid & P6 & 0,694 & 0,01 & Valid \\
\hline $\mathrm{D} 2$ & 0,528 & 0,01 & Valid & P7 & 0,661 & 0,01 & Valid \\
\hline D3 & 0,674 & 0,01 & Valid & & & & \\
\hline D4 & 0,614 & 0,01 & Valid & & & & \\
\hline D5 & 0,607 & 0,01 & Valid & & & & \\
\hline D6 & 0,539 & 0,01 & Valid & & & & \\
\hline D8 & 0,647 & 0,01 & Valid & $\cdot$ & & & \\
\hline D9 & 0,575 & 0,01 & Valid & & & & \\
\hline D10 & 0,597 & 0,01 & Valid. & & & 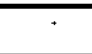 & \\
\hline D11 & 0,657 & 0,01 & Valid & & & & \\
\hline D12 & 0,701 & 0,01 & Valid & & & & \\
\hline D13 & 0,641 & 0,01 & Valid & & & & \\
\hline
\end{tabular}


Khusniyah Purwani: Important and Performance Analysis...

Mendasarkan tabel di atas diketahui bahwa hampir seluruh butir pertanyaan sahih atau valid, dengan nilai korelasi pearson diatas 0,4 , signifikan pada level 0,01. Berdasarkan pengujian tersebut setiap butir berkorelasi positif terhadap skor total dengan signifikansi pada level 0,01 . Semua butir valid (sahih) kecuali butir Kurikulum 3, Kurikulum 4, dan Dosen 7.

\section{D.2.2. Uji Reliabilitas}

Uji keandalan (reliabilitas) digunakan untuk mengukur bahwa instrumen penelitian ini benar-benar bebas dari kesalahan (error) sehingga menghasilkan hasil yang konsisten sehingga dapat berlaku pada kondisi yang berbeda-beda (Cooper dan Emory, 1995, p.153). Pertanyaan-pertanyaan yang telah valid diuji berikutnya dengan konsistensi internal untuk mengetahui sejauh mana pengukuran yang telah dilakukan dalam penelitian ini dapat dipercaya atau dapat diandalkan. Teknik Alpha dari Cronbach dengan indeks konsistensi reliabilitas diatas 0,7 merupakan teknik pengujian konsistensi reliabilitas antar item yang paling popular dan menunjukkan indeks konsistensi reliabilitas yang cukup sempurna (Sekaran, 1992). Uji keandalan item-item pertanyaan menggunakan Reliability Analysis (SPSS 13.0.for Windows). Diperoleh nilai reliabelitas data penelitian seperti tersaji dalam Tabel 3 , semua variabel telah reliable atau andal.

Tabel 3.

Hasil Uji Reliabilitas

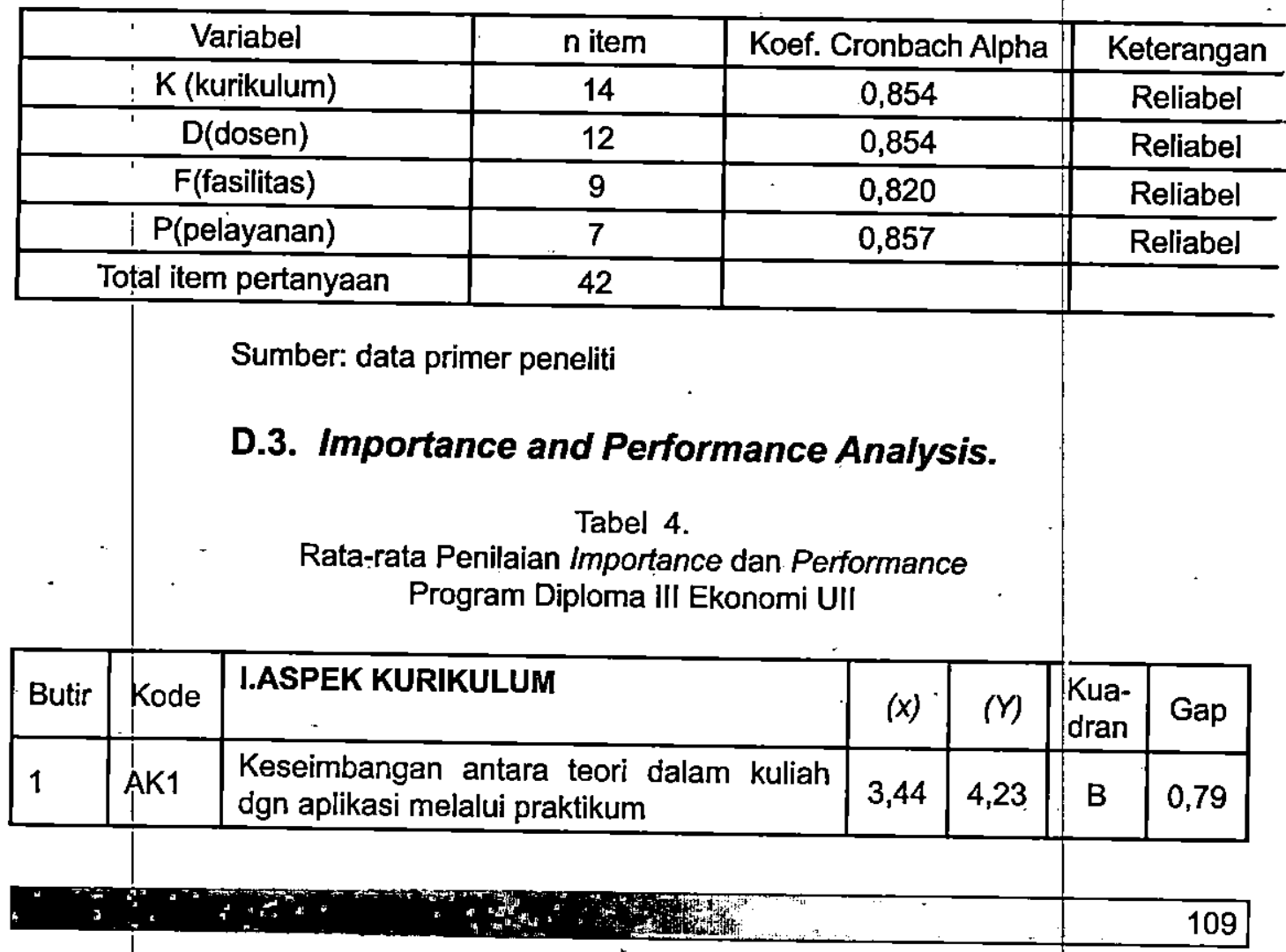




\begin{tabular}{|c|c|c|c|c|c|c|}
\hline 2 & AK2 & $\begin{array}{l}\text { Mata kuliah (MK) yang ditawarkan prodi } \\
\text { memenuhi kebutuhan mahasiswa untuk } \\
\text { diaplikasikan di dunia kerja }\end{array}$ & 3,75 & 4,33 & B & 0,58 \\
\hline 5 & AK5 & $\begin{array}{l}\text { Tersedia software pendukung keahlian } \\
\text { program studi yang digunakan dalam } \\
\text { praktikum }\end{array}$ & 3,46 & 3,77 & D & 0,31 \\
\hline 6 & AK6 & $\begin{array}{l}\text { Tersedia - software pendukung mata } \\
\text { kuliah kompetensi program studi di dalam } \\
\text { laboratorium : }\end{array}$ & 3,49 & 4,28 & B & 0,80 \\
\hline 7 & AK7 & $\begin{array}{l}\text { Tersedia Modul yang dibuat oleh dosen } \\
\text { pengampu Cukup memfasilitasi kebutuhan } \\
\text { saat kuliah/. }\end{array}$ & 3,42 & 4,31 & B & 0,89 \\
\hline 8 & AK8 & $\begin{array}{l}\text { Tersedia modul pendukung untuk kuliah } \\
\text { praktikum Di laboratorium computer }\end{array}$ & 3,20 & 4,29 & A & 1,09 \\
\hline 9 & AK9 & $\begin{array}{l}\text { Tersedia kesesuaian modul dengan materi } \\
\text { kuliah }\end{array}$ & 3,58 & 4,28 & B & 0,71 \\
\hline 10 & AK10 & $\begin{array}{l}\text { Pengaplikasian mata kuliah melalui } \\
\text { praktikum sudah sesuai }\end{array}$ & 3,19 & 4,24 & A & 1,06 \\
\hline 11 & AK11 & $\begin{array}{l}\text { Asisten Laboratorium cukup memadai/ } \\
\text { dalam kegiatan mengasisteni matakuliah } \\
\text { praktikum di lab. Komputer }\end{array}$ & 2,64 & 4,18 & $\dot{A}$ & 1,54 \\
\hline 12 & AK12 & $\begin{array}{l}\text { Asisten telah Menguasai materi praktikum } \\
\text { di lab. Komputer }\end{array}$ & 2,83 & 3,90 & C & 1,07 \\
\hline 13 & AK13 & $\begin{array}{l}\text { Penyampaian materi praktikum oleh asisten } \\
\text { lab. mudah dipahami }\end{array}$ & 2,78 & 3,85 & C & 1,06 \\
\hline 14 & AK14 & $\begin{array}{l}\text { Waktu masuk/ selesai praktikum asisten } \\
\text { lab. disiplin }\end{array}$ & 2,90 & $3 ; 79$ & C & 0,90 \\
\hline 15 & AK15 & $\begin{array}{l}\text { Mata kuliah teori telah memenuhi } \\
\text { perkembangan dunia bisnis dewasa ini }\end{array}$ & 3,42 & 3,90 & D & 0,48 \\
\hline 16 & AK16 & $\begin{array}{l}\text { Mata kuliah praktikum sudah dapat } \\
\text { memenuhi kebutuhan perkembangan bisnis } \\
\text { aplikasi }\end{array}$ & 3,35 & 3,87 & D & 0,52 \\
\hline & & II. ASPEK DOSEN & & & & \\
\hline 17 & AD1 & $\begin{array}{l}\text { Dosen cukup jelas dalam memberikan } \\
\text { materi kuliah }\end{array}$ & 3,49 & $4 ; 17$ & B & 0,69 \\
\hline 18 & $\mathrm{AD} 2$ & $\begin{array}{l}\text { Dosen dalam mengajarkan materi seșuai } \\
\text { silabus. }\end{array}$ & 3,65 & 4,11 & B & 0,46 \\
\hline 19 & AD3 & $\begin{array}{l}\text { Dosen tepat - waktu - masuk mengajar di- } \\
\text { kelas }\end{array}$ & 2,87 & 4,24 & A & 1,37 \\
\hline
\end{tabular}


Khusniyah Purwani: Important and Performance, Analysis...

\begin{tabular}{|c|c|c|c|c|c|c|}
\hline 20 & AD4 & $\begin{array}{l}\text { Dosen mengakhiri perkuliahan dalam } \\
\text { rentang waktu tertoleransi (waktu tidak } \\
\text { terkurangi/ menambah waktu banyak) }\end{array}$ & 3,10 & 4,19 & $\mathbf{A}$ & 1,08 \\
\hline 21 & AD5 & $\begin{array}{l}\text { Dosen terbuka/ welcome untuk konsultasi } \\
\text { akademik di dalam/ di luar jam mengajar di } \\
\text { kelas }\end{array}$ & 3,58 & 3,85 & D & 0,27 \\
\hline 22 & AD6 & $\begin{array}{l}\text { Telah terdapat kesesuaian materi dengan } \\
\text { silabus }\end{array}$ & 3,52 & 3,83 & $\mathbf{D}$ & 0,31 \\
\hline 24 & AD8 & $\begin{array}{l}\text { Dosen dlm "memberi nilai MK kpd } \\
\text { mahasiswa telah transparan, adil/ sesuai } \\
\text { ketentuan program" }\end{array}$ & 3,33 & 4,22 & B & 0,89 \\
\hline 25 & AD9 & $\begin{array}{l}\text { Dosen . telah memberikan tugas-tugas } \\
\text { pendukung MK kepada mahasiswa }\end{array}$ & 3,78 & 4,03 & D & 0,24 \\
\hline 26 & AD10 & $\begin{array}{l}\text { Dosen tepat waktu dalam mengeluarkan } \\
\text { hasil ujian }\end{array}$ & 2,87 & 3,81 & C & 0,94 \\
\hline 27 & AD11 & $\begin{array}{l}\text { Dosen aktif memberikan materi dalam } \\
\text { mengajar }\end{array}$ & 3,58 & 4,01 & $\mathbf{D}$ & 0,44 \\
\hline 28 & AD12 & $\begin{array}{l}\text { Dosen telah memberi tanggapan/ jawaban } \\
\text { dg jelas bilamana mendapat pertanyaan } \\
\text { dari mahasiswa }\end{array}$ & 3,68 & 4,00 & D & 0,32 \\
\hline 29 & AD13 & $\begin{array}{l}\text { Dosen siap/ menguasai materi dalam } \\
\text { mengajar di kelas }\end{array}$ & 3,76 & 3,90 & D & 0,14 \\
\hline & & III. ASPEK FASILITAS & & & & \\
\hline 30 & AF1 & Ruang kuliah nyaman & 2,92 & 4,01 & C & 1,09 \\
\hline 31 & AF2 & $\begin{array}{l}\text { Fasilitas ruang kuliah telah memenuhi } \\
\text { kebutuhan proses belajar mengajar }\end{array}$ & 2,58 & 4,15 & A & 1,57 \\
\hline 32 & AF3 & Fasilitas Laboratorium Komputer lengkap & 2,47 & 4,27 & A & 1,80 \\
\hline 33 & AF4 & $\begin{array}{l}\text { Terdapat fasilitas. Lab. Pendukung mata } \\
\text { kuliah (lab. bahasa, Lab. bank, lab. } \\
\text { manajemen, lab. akuntansi) }\end{array}$ & 2,84 & 4,18 & A & 1,34 \\
\hline 34 & AF5 & $\begin{array}{l}\text { Penataan ruangan Lab. Komputer yang } \\
\text { representatif }\end{array}$ & 2,94 & 4,15 & A & 1,20 \\
\hline 35 & AF6 & $\begin{array}{l}\text { Tersedia fasilitas anjungan komputer bagi } \\
\text { mahasiswa }\end{array}$ & 2,44 & 4,08 & $\mathrm{C}$ & 1,54 \\
\hline 36 & AF7 & $\begin{array}{l}\text { Di beberapa titik tersedia area bebas } \\
\text { intemet/ hot spot area }\end{array}$ & 2,63 & 4,09 & A & 1,46 \\
\hline
\end{tabular}


APLIKASI BISNIS, Volume 8 No 2, Juni 2009.

ISSN: $1411-4054$

\begin{tabular}{|l|l|l|c|c|c|c|}
\hline 37 & AF8 & $\begin{array}{l}\text { Tersedia fasilitas tempat ibadah/ musholla } \\
\text { yang representatif }\end{array}$ & 3,59 & 4,01 & D & 0,42 \\
\hline 38 & AF9 & Tersedia fasilitas kantin buat mahasiswa & 3,60 & 4,13 & B & 0,53 \\
\hline & & V. ASPEK PELAYANAN & & & & \\
\hline 39 & AP1 & $\begin{array}{l}\text { Pelayanan pimpinan/ pengelola Program } \\
\text { D3 memadai }\end{array}$ & 2,91 & 4,26 & A & 1,35 \\
\hline 40 & AP2 & $\begin{array}{l}\text { Pelayanan karyawan administratif akademik } \\
\text { memadai }\end{array}$ & 3,10 & 4,35 & A & 1,26 \\
\hline 41 & AP3 & $\begin{array}{l}\text { Pelayanan karyawan administratif keuangan } \\
\text { memadai }\end{array}$ & 3,19 & 4,33 & A & 1,13 \\
\hline 42 & AP4 & $\begin{array}{l}\text { Pelayanan karyawan administratif } \\
\text { perpustakaan memadai }\end{array}$ & 3,26 & 4,05 & D & 0,79 \\
\hline 43 & AP5 & $\begin{array}{l}\text { Pelayanan karyawan bagian umum dan } \\
\text { sekretaris memadai }\end{array}$ & 3,12 & 4,08 & C & 0,96 \\
\hline 44 & AP6 & $\begin{array}{l}\text { Pelayanan karyawan keamanan/ SATPAM } \\
\text { memadai }\end{array}$ & 3,21 & 4,07 & D & 0,86 \\
\hline 45 & AP7 & Pelayanan karyawan parkir memadai & 3,15 & 4,01 & C & 0,86 \\
\hline & & $\begin{array}{l}\text { Rata-rata dari nilai rata-rata performance } \\
\text { dan importance }\end{array}$ & 3,20 & 4,09 & & \\
\hline
\end{tabular}

Tabel 4 di atas menunjukkan bahwa sebanyak 42 butir indikator penilaian kepuasan mahasiswa terbagi ke dalam empat kuadran, kuadran $A, B, C$ dan $D$. Kolom satu menunjukkan urutan butir, kolom kedua adalah kode butir, kolom ke 3 adalah ăspek-aspek penilaian kepuasan mahasiswa, kolom keempat menunjukkan hasil penilaian mahasiswa terhadap kinerja, kolom kelima hasil penilaian mahasiswa terhadap harapan, kolom keenam berisi kategori kuadran dan kolom ke tujuh menunjukkan kesenjangan (gap) antara harapan yang diinginkan oleh mahasiswa dengan kinerja Program Diploma.

Tabel itu menunjukkan tiga belas (13) butir masuk kedalam kuadran A, sembilan (9) butir berada pada kuadran B, delapan (8) butir berada pada kuadran $C$ dan dua belas (12) butir masuk di kuadran $D$. Sementara itu untuk diagram kartesius hasil nilai rata rata kinerja dan harapan mahasiswa nampak dalam Gambar 4 di bawah ini. Dari diagram ini dapat diketahui atribut/ butirbutir mana saja yang merjadi prioritas utama untuk diperbaiki agar menjadi lebih baik. 
Khusniyah Purwani: Important and Performance Analysis...

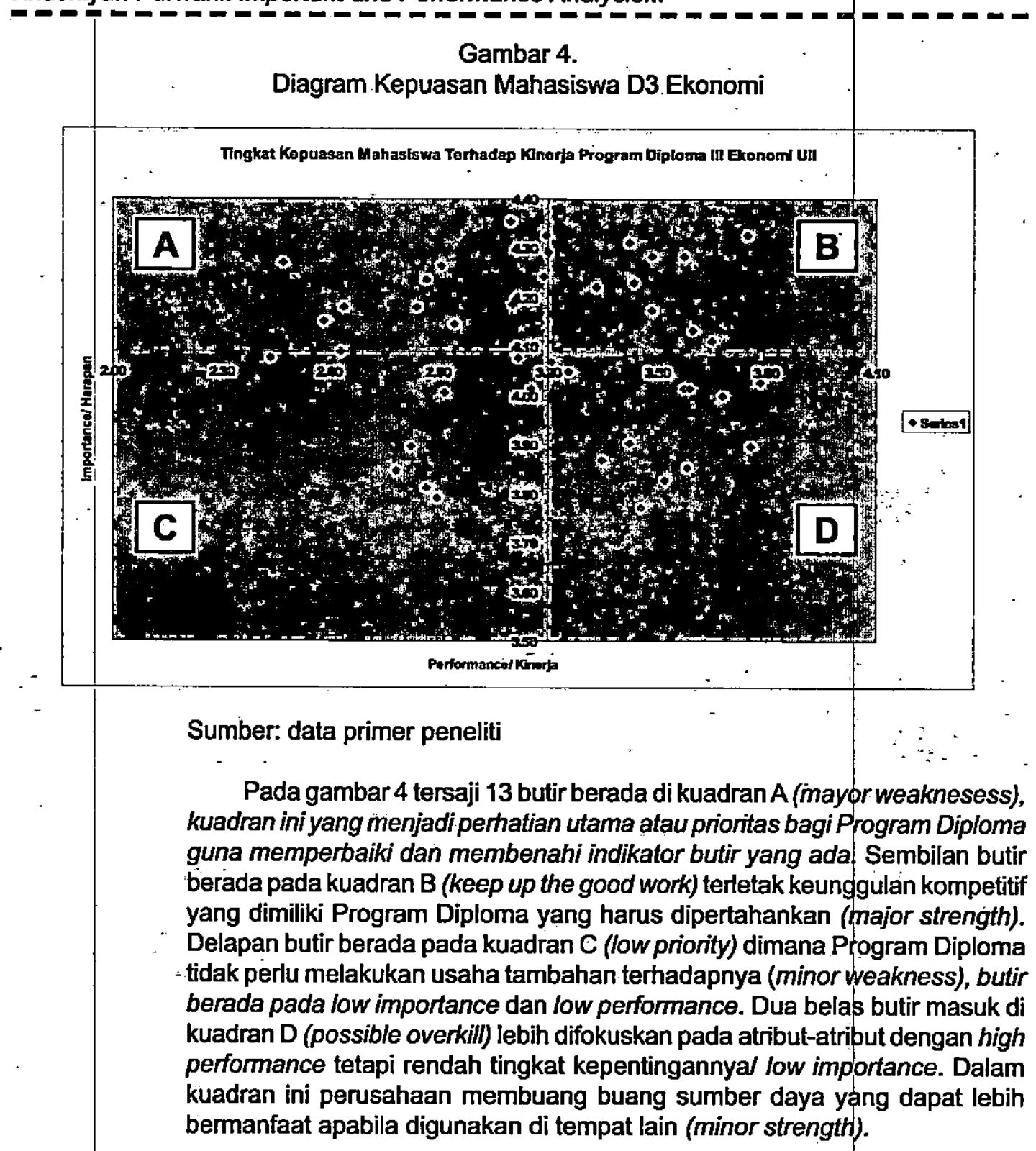

Gambar 4. 
TABEL 5

Aspek-Aspek Penilaian Kepuasan Mahasiswa yang Masuk Kuadran A .

\begin{tabular}{|c|c|c|c|c|c|c|c|}
\hline Butir & Kode & $\begin{array}{l}\text { Aspek-Aspek Penilaian Mahasiswa } \\
\text { yang Masuk dalam Kuadran A }\end{array}$ & $(x)$ & $(Y)$ & Gap & $\begin{array}{c}\% \\
\text { Gap }\end{array}$ & Rank \\
\hline 32 & AF3 & $\begin{array}{l}\text { Fasilitas Laboratorium Komputer } \\
\text { lengkap }\end{array}$ & 2,47 & 4,27 & 1,80 & 42 & 1 \\
\hline 31 & AF2 & $\begin{array}{l}\text { Fasilitas ruang kuliah telah memenuhi } \\
\text { kebutuhan proses belajar mengajar }\end{array}$ & 2,58 & 4,15 . & 1,57 & 38 & 2 \\
\hline 11 & AK11 & $\begin{array}{l}\text { Asisten Laboratorium cukup memadai/ } \\
\text { dalam kegiatan mengasisteni } \\
\text { matakuliah praktikum di lab. Komputer }\end{array}$ & 2,64 & 4,18 & 1,54 & 36 & 3 \\
\hline 36 & AF7 & $\begin{array}{l}\text { Di beberapa titik tersedia area bebas } \\
\text { internet/ hot spot area }\end{array}$ & 2,63 & 4,09 & 1,46 & 36 & 4 \\
\hline 19 & AD3 & $\begin{array}{l}\text { Dosen tepat waktu masuk mengajar } \\
\text { di kelas }\end{array}$ & 2,87 & 4,24 & 1,37 & 32 & 5 \\
\hline 39 & AP1 & $\begin{array}{l}\text { Pelayanan pimpinan/ pengelola } \\
\text { Program D3 memadai }\end{array}$ & 2,91 & 4,26 & 1,35 & 32 & 6 \\
\hline 33 & AF4 & $\begin{array}{l}\text { Terdapat fasilitas Lab. Pendukung } \\
\text { mata kuliah (lab. bahasa, Lab. bank, } \\
\text { lab. manajemen, lab. akuntansi) }\end{array}$ & 2,84 & 4,18 & 1,34 & 32 & 7 \\
\hline 40 & AP2 & $\begin{array}{l}\text { Pelayanan karyawan administratif } \\
\text { akademik memadai }\end{array}$ & 3,10 & 4,35 & 1,26 & 29 & 8 \\
\hline 34 & AF5 & $\begin{array}{l}\text { Penataan ruangan Lab. Komputer } \\
\text { yang representatif }\end{array}$ & 2,94 & 4,15 & 1,20 & 29 & 9 \\
\hline 41 & AP3 & $\begin{array}{l}\text { Pelayanan karyawan administratif } \\
\text { keuangan memadai }\end{array}$ & 3,19 & 4,33 & 1,13 & 26 & 10 \\
\hline 20 & AD4 & $\begin{array}{l}\text { Dosen mengakhiri perkuliahan dalam } \\
\text { rentang waktu tertoleransi (waktu } \\
\text { tidak terkurangi/ menambah waktu } \\
\text { banyak) }\end{array}$ & 3,10 & 4,19 & 1,08 & 26 & 12 \\
\hline 8 & AK8 & $\begin{array}{l}\text { Tersedia modul pendukung untuk } \\
\text { kuliah praktikum Di laboratorium } \\
\text { computer }\end{array}$ & 3,20 & 4,29 & 1,09 & 25 & 11 \\
\hline 10. & AK10 & $\begin{array}{l}\text { Pengaplikasian mata kuliah melalui } \\
\text { praktikum sudah sesuai }\end{array}$ & 3,19 & 4,24 & 1,06 & 25 & 13 \\
\hline
\end{tabular}

Tabel 5 menyajikan butir-butir atribut yang perlu mendapat prioritas perbaikan dan pembenahan oleh Program Diploma secara berurutan berdasar rankingnya. Urutan itu menunjukkan \% kesenjangan antara harapan dengan kinerja yang diterima mahasiswa. 
Khusniyah Purwani: Important and Performance Analysis...

Gambar 5.

Diagram Aspek-Aspek Penilaian Mahasiswa yang Masuk Kuadran A

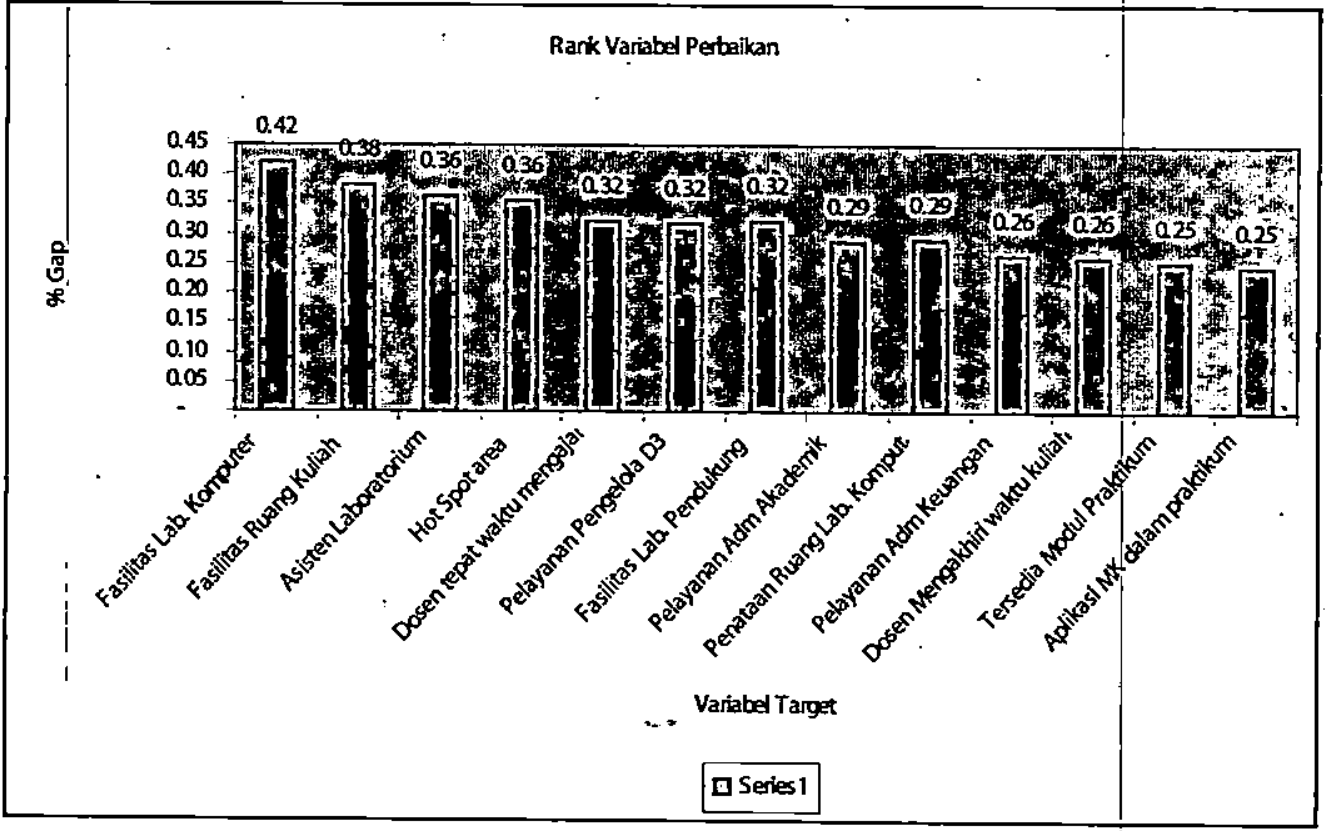

Urutan ke tigabelas atribut yang harus dibenahi dan diperbaiki oleh Program dan besar prosentase (\%) kesenjangan antara harapan dengan kinerja, dari yang terpenting terlebih dahulu adalah:

1) Fasilitas laboratorium komputer, sebesar $42 \%$

2) Fasilitas ruang kuliah memenuhi kebutuhan proses perkuliahan, sebesar $38 \%$

3) Asisten laboratorium cukup memadai/ dalam kegiatan asistensi matakuliah praktikum di Lab. Komputer, $36 \%$

4) Di beberapa titik tersedia hot spot area, $36 \%$

5) Dosen tepat waktu saat masuk mengajar di kelas, sebesar $32 \%$

6) Pelayanan pimpinan/ pengelola Program D3 memadai, $32 \%$

7) Terdapat fasilitas lab. pendukung mata kuliah (Lab. Bank, Lab. Manajemen, dan Lab. Akuntansi), 32\%

8) Pelayanan karyawan administratif akademik memadai, $29 \%$

9) Penataan ruang Lab. Komputer yang representative, $29 \%$

10) Pelayanan karyawan administratif keuangan memadai, $26 \%$

11) Dosen mengakhiri perkuliahan dalam batas toleransi (terkurangi/ menambah) waktu terlalu banyak, $26 \%$

12) Tersedia modul pendukung praktikum di Laboratorium Komputer, $\leq 5 \%$

13) Aplikasi mata kuliah melalui praktikum sudah sesuai, $25 \%$ 
Hasil penelitian ini menunjukkan bahwa sebanyak empat puluh dua (42) atribut pengukuran terbagi kedalam empat kuadran. Kuadran A (concentrate here) terisi sebanyak $31 \%$ (13 atribut), menjadi prioritas utama untuk dibenahi. Pada kuadran ini jelas terlihat bahwa mahasiswa merasa tidak puas, ditunjukkan dengan nilai kenyataan yang berada di bawah harapan. Program Diploma perlu memperhatikan atribut-atribut yang masuk kuadran ini, karena di sinilah letak kelemahan Program Diploma III Ekonomi Ull. Sembilan atribut (21\%) masuk kuadran B (keep up the good work), menunjukkan keunggulan kompetitif yang dimiliki oleh Program Diploma sehingga perlu untuk dipertahankan. Pada kuadran ini mahasiswa merasa puas dengan atribut yang telah diberikan oleh Program Diploma.

Sebanyak $18 \%$ (delapan atribut) berada di kuadran C (Jow priority), atribut ini tidak membutuhkan usaha tambahan terhädapnya. Atribut pada kuadran ini mempunyai kinerja rendah namun tingkat harapan mahasiswa juga rendah, jadi tidak perlu dilakukan pembenahan lagi. Dua belas atribut ( $29 \%$ dari total atribut) berada di kuadran D (possible overkil), dimana perusahaan membuang buang sumber daya yang dapat lebih bermanfaat apabila digunakan di tempat lain. Pada kuadran ini diperoleh kinerja Program tinggi, namun sesungguhnya harapan mahasiswa terhadap atribut di sini rendah, sehingga alangkah baik bila hal ini diabaikan.

Tingkat kesenjangan antara jasa pelayanan yang diterima dengan jasa pelayanan yang diharapkan mahasiswa berkisar dari $25 \%$ hingga $42 \%$. Dengan demikian tingkat kesesuaian antara jasa pelayanan yang diterima mahasiswa dibandingkan dengan jasa pelayanan yang diharapkan mahasiswa berkisar $58 \%-75 \%$, yang berarti bahwa kesenjangan yang ada perlu mendapat perhatian serius oleh Program Diploma. Mahasiswa akan merasa puas apabila sesuai antara apa yang diterima atau dirasakan dengan apa yang diharapkan. Apabila tingkat kesenjangan antara pelayanan yang diterima dengan yang diharapkan berkisar antara minimal $25 \%$ dan maksimal $42 \%$, hal ini menunjukkan mahasiswa baniyak merasa tidak puas.

Sedangkan atribut yang masuk kategori prioritas utama dalam upaya perbaikan, pembenahan dan peningkatan terus menerus (continual improvement) adalah: atribut pembenahan fasilitas lab. komputer, pembenahan fasilitas ruang perkuliahan, asisten laboratorium, perlu tersedia hot spot area, dosen tepat waktu saat masuk mengajar, pelayanan pengelola Program D3, - pembenahan fasilitas lab. pendukung mata kuliah (Lab.Bank, Lab.Manajemen, dan Lab.Akuntansi), pelayanan karyawan administratif akademik, penataan ruang lab. Komputer, pelayanan karyawan administratif keuangan, dosen mengakhiri perkuliahan dalam batas toleransi (terkurangi/menambah) waktu terlalu banyak, ketersediaan modul praktikum, dan atribut aplikasi mata kuliah melalui praktikum. 


\section{Saran}

Saran dalam penelitian ini adalah bahwa penggunaan Importance and Performance Analysis (IPA) memiliki kelemahan yakni tidak/bisa mengidentifikasi proses yang sedang berjalan, sehingga pertu menggunakan metode lain. Sebagai misal Kano Model Analysis bisa digunakan uthuk mengetahui tingkat kepuasan responden selama proses pelayanan jasa berlangsung. Bisa pula dilakukan dengan menggabungkan Kano model analysis dan IPA analysis sehingga diperoleh Modified IPA Analysis. Penelitian akan lebih fokus pula apabila responden yang diteliti dibedakan berdasarkan program studinya, karena masing-masing prodi mempunyai kebijakan yang berbeda, sehingga besar kemungkinan respon mahasiswa masing-masing prodi juga berbeda.

\section{DAFTAR PUSTAKA}

Anderson, E.W. and Mittal, V. (2000), "Strengthening The Satisfaction-Profit Chain", Journal of Service Research, Vol. 3 No. 2, pp. 107-1290.

Caceres, Ruben C and Nicholas G. Paparoidamis (2005), "Service Quality, Relationship Satisfaction;-Trust, CommitmentAnd Business-To-Business Loyalty", European Joumal of Marketing, Vol. 41 No. 7/8, 2007, pp. 836-867

Cooper \& Emory (1995), Business Research Methods, 5 th ed, Richard D. IRWIN, Inc

Crosby, L.A. and Stevens, N. (1987), "Effects Of Relationship Marketing On Relationship Satisfaction, Retention And Prices In The Life Insurance Industry", Journal of Marketing Research, Vol. 24 No. 4, pp. 404-11.

Ge'rson, Tontini and Ame"lia Silveira (2007), "Identification Of Satisfaction Attributes Using Competitive Analysis Of The Improvement Gap", International Journal of Operations \& Production Management, Vol. 27 No. 5 , pp. $482-500$

Gro"nroos, C. (1984), "A Service Quality Model And Its Marketing Implications", European Journal of Marketing, Vol. 18 No. 4, pp. 36-44

Martilla, J.A. and James, J.C. (1977), "Importance-Performance Analysis", Joumal of Marketing, Vol. 41, pp. 77-9.

Mittal, V., Kumar, P. and Tsiros, M. (1999), “Attribute-Level Performance, Satisfaction, And Behavioral Intentions Over Time: A ConsumptionSystem Approach", Journal of Marketing, Vol. 63, pp. 88-101. 
Oliver, R.L. (1997), "Satisfaction: Behavioral Perspective on the Consumer", McGraw-Hill, New York, NY.

Parasuraman, A., Zeithaml, V.A. and Berry, L.L. (1988), "Servqual:AMultipleItem Scale For Measuring Consumer Perceptions Of Service Quality", Joumal of Retailing, Vol. 64 No. 1, pp. 12-40.

Sekaran, Uma (1992), Research Methods For Business: A Skill Building Approach, Second Edition, New York Chichester Brisbone Toronto Singapore, John Willey \& Sons, Inc.

Simha R. Magal, et.al. (2009):"Using Importance Performance Analysis To Understand And Guide E-Business Decision Making:In Smes", Joumal of Enterprise Information Management, Vol. 22 No. 1/2,2009, pp. 137151 